\title{
Adapting to the Changing Academic Job Market
}

PAUL F. DIEHL

$s$ part for an external review team for an unnamed university, I had the opportunity to interview doctoral students in what is a top-40 graduate program. When asked what their career aspirations were, nine of the ten respondents expected a tenure-track job at a Research I university. Although such hopes might be collectively unrealistic at any juncture, they are especially improbable in light of substantial changes in the academic job market.

There are now fewer entry-level, tenure-track faculty positions in political science (and many other disciplines as well) than there were in previous decades. Accordingly, there is an over-supply of qualified candidates relative to the number of academic jobs available to them. Thus, many newly minted PhDs have little or no prospect of securing the brass ring of a tenure track job, whether immediately after graduating or indeed ever. There are multiple explanations for this circumstance. State funding for public universities has declined on an adjusted, and in some cases absolute, basis; the heyday of higher education expansion is well past for virtually every state in the United States (and for many other countries as well). Private colleges, especially those highly dependent on tuition revenue, have experienced fiscal pressures, and a few have actually ceased operations. The COVID pandemic has made these trends worse, although it is not clear what the long-term implications will be, both for the pandemic itself and higher education more specifically.

Two other factors further decrease available academic jobs. One is the secular trend toward colleges and universities hiring contingent or non-tenure system faculty (full-time renewable, full-time temporary, and part-time adjuncts) for instruction; some reports indicate as many as $70 \%$ of teaching positions are occupied by what has been described as an academic underclass-those who teach many more courses for far less pay and with no job security as compared to tenure system faculty. In addition, projections of ample academic job opportunities made in the 1970s through the 1990s were based on two assumptions, now determined to be false. Faculty have not necessarily retired as quickly as they once did, given increased longevity and the elimination of mandatory retirement age in the United States and elsewhere. Furthermore,

Paul F. Diehl is Henning Larsen Professor Emeritus of Political Science at the University of Illinois at Urbana-Champaign. He is also Ashbel Smith Professor Emeritus of Political Science at the University of Texas-Dallas, where he was Associate Provost and Director of the Center for Teaching and Learning. He is past President of the Peace Science Society (International) and past President of the International Studies Association. His areas of expertise include the causes of war, UN peacekeeping, and international law. even those who did retire were not necessarily replaced on a 1-to1 basis as was anticipated.

Given the diminished and uncertain academic job market, what kind of adjustments have doctoral programs in political science made or could make in the coming years? This essay addresses some of these choices, which are not necessarily mutually exclusive. In discussing these options, I also lay out some of the costs or tradeoffs attendant to each, as no panaceas exist.

\section{REDUCING ADMISSIONS}

One adaptation to the evolving academic job market has been for graduate programs to reduce admissions. This can be portrayed as an ethical response in that graduate programs should not produce substantially more $\mathrm{PhDs}$ than the market will bear, and programs don't want to make promises about future job prospects that can't be fulfilled. Less altruistically, such a move allows departments to consolidate funding and offer multiyear aid packages to incoming students and thereby remain competitive with other doctoral programs. The adaptation is also designed to prevent adverse reputational costs to programs that produce large numbers of graduates who cannot secure desired employment.

Reducing admissions relies on projections about the size and configuration of what the market will bear for one's students (as these can vary substantially depending on the university and program). Doctoral programs are notoriously inefficient in terms of yield from initial admission to completion of the dissertation; for some disciplines, it is as low as $30 \%$. Estimating wrongly and with differential drop-out rates per cohorts, some programs can have a shortage of students for given years.

Fewer doctoral students also includes some negative spillover effects for a department. It means fewer research and teaching assistants available. This could increase the workloads of faculty or affect other things such as class size. Many faculty desire to teach graduate courses on a regular basis, reflective of their own personal instructional preferences or tied into their research agendas. There could be fewer students to distribute across the graduate curriculum, and perhaps fewer course offerings both in total and within subdisciplines. Faculty and student unhappiness is likely to result. Schools with separate masters and "fast-track" (combined BA/MA degree programs) can channel those students into the same courses as doctoral students. This might happen in any case, but it does address the course offerings shortage as well. Nevertheless, there are instructional challenges in these mixed classrooms with student orientations (policy vs. scholarly research), abilities, and career goals. It is not clear that each audience is served well by placing them in 
the same course.

\section{MORE EMPHASIS TO PEDAGOGICAL TRAINING}

A more significant change to doctoral programs in political science is shifting some of the emphasis from research preparation to training and experience in pedagogy. Many doctoral candidates have limited background in teaching, with fellowships and research assistantships excluding opportunities to serve as teaching assistants; even when the latter occurs, graduate students might do little more than hold office hours and do the grading for faculty instructors. Doctoral students might also receive little or no training in teaching or exposure to the scholarship of teaching and learning, a dramatic contrast to the coverage they receive in the research literature in political science.

A greater emphasis on teaching in graduate programs has several purposes. First, it makes students, who might previously have landed jobs at Research I institutions, more competitive for tenure-system positions at smaller universities and colleges that have a central teaching mission. Training in pedagogy would also ease their transitions and improve their performance once they secured those positions. Second, better instructional preparation would match the requirements for graduates who accept contingent faculty positions. Such positions with titles such as "lecturer" or "assistant professor of instruction" are increasingly common in higher education; these involve little or no research responsibilities, but more extensive teaching ones.

Providing better training in pedagogy could involve several initiatives, well short of creating actual degrees or specializations that are in place for other disciplines (e.g., PhD in the Teaching of Physics). These might include (1) offering a credit or non-credit class on teaching for students, (2) expanding teaching opportunities for ABDs, and (3) hiring one's own graduates as teaching post-docs as a bridge to entering the academic job market. Departments could also encourage their students to take advantage of university-wide offerings, such as teaching certificate programs, that provide training and certification in pedagogy.

Paradoxically, expanding the teaching opportunities for graduate students could undermine department claims on new or replacement faculty positions to meet any enrollment pressures. Financially, paying one's own graduate students to teach is more costly (salary and benefits) than the equivalent of hiring adjunct instructors on a course-by-course basis.

\section{CUTTING PROGRAMS}

The shrinking academic job market affords an opportunity to cull weak doctoral programs, ones that perhaps should be eliminated anyway. There is a tendency to create new programs in universities. These have no sunset clauses and thus persist perhaps long after their usefulness. Eliminating these problems would reduce the supply of new PhDs and thus make it more likely that those who do earn this highest degree will be able to secure an academic job.

A key consideration is what criteria might be used to identify candidates for termination. Let me propose several. One would be to eliminate programs that have not been able to place their graduates well in the past, defined according to aspiration level. That standard alone is probably insufficient. Another consideration is eliminating programs that produce very small numbers of gradvates every few years and/or suffer from high attrition rates. More strategically, and particularly relevant for public institutions, would be to terminate programs that are offered better elsewhere on a university system or regional basis.

Inertia is a strong force in organizations, no less in colleges and universities. One will swim against the tide in attempting to eliminate programs, and that tide will be bolstered by faculty resistance to it in the affected departments. Many faculty and departments define their reputation in terms of having doctoral programs in political science and will see themselves as diminished if those programs no longer exist. Cutting doctoral programs might be a rational decision at the collective level for those in the orbit of the American Political Science Association, but this option is only effective when a number of departments are willing to take this action. The necessity of multiple, individual decisions is one reason why it would be difficult to achieve.

\section{ADAPTING THE CURRICULUM}

Reducing admissions, enhancing training in teaching, and eliminating programs reflect changes in the demand for university and college professors, but they do not recognize alternatives to that market. There might be no need to reduce the number of new political science PhDs if they can be successfully placed outside of academia. Yet this requires some changes in how students are trained and what assistance they are given in finding alternative jobs.

One adaptation that does recognize that other employment is possible for political science PhDs is changing the curriculum or at least emphasizing certain aspects of it. In states such as Texas, there are political pressures and new mandates for "marketable skills," concentrated on undergraduate courses and degrees. The same impetus is not present for graduate programs, but there are lessons to be derived from the idea.

Advanced political science degree holders are qualified for many positions outside of academia and can apply their skill sets to such employment. APSA has created a Careers Diversity Committee to facilitate that end. Most obvious would be those graduates who have advanced quantitative skills, and these open up opportunities for jobs in collecting and analyzing data as well as modeling. In an era of "big data," this is a growth area for positions in government, non-governmental organizations, and the private sector. Historically, political scientists have filled positions associated with survey research, but now the range of possibilities is much greater. Traditional single country or geographic area expertise is also a valued commodity in certain sectors outside of academic settings. The aforementioned APSA committee also aptly notes that "[g] overnance, justice, power, and ethics are issues that are pervasive across all institutions," and therefore could be benefit from expertise in those areas held by political science graduates.

To ensure that doctoral students are qualified for such positions, graduate programs might need to offer a wider range of courses, especially in methodology, including cutting edge approaches (e.g., visualization, big data) and the like. Advising students to take additional courses or training beyond minimum degree requirements would encourage broader skill sets. Adaptations used in other disciplines such as business or engineering - such as internships-might be less applicable to political science, but there is room for innovation for departments to establish partnerships that provide training and experience for the non-academic market.

Clearly, the marketable skills approach is better suited for some graduate students than others, relatively privileging those in quantitative methodology versus those whose expertise lies in political philosophy for example. Faculty are also likely to be resistant to this adaptation, as too often jobs outside of academia are 
perceived to be consolation prizes or those appropriate for only weaker students.

\section{CAREER GUIDANCE}

If departments make adjustments to meet the needs of nonacademic markets, they can't stop there. There needs to be commensurate assistance for students to identify and secure those positions. To the extent that doctoral students in political science already receive help in obtaining employment, most comes in the forms of practice job talks, workshops on publishing, and the like-all geared toward the academic job market.

Many political science faculty are ill-suited to provide career assistance outside of academia; most have never held a job outside of the academic context. To get up to speed, faculty members will need to educate themselves about opportunities outside of academia and take advantage of webinars and training sessions offered by APSA and other professional associations. Making non-academic jobs salient and achievable in the eyes of graduate students is also necessary. This can be done by raising the prospects and providing information about non-academic placement during orientation and the first year of graduate study. Bringing successful alumni who hold those kind of positions back to campus can provide inspiration to students, but also offer the kinds of connections and dialogue with those outside the ivy walls to which academic institutions aspire.

Political science and related departments are unlikely to accomplish career advice on their own, or at least would benefit from assistance available on their campuses. Normally, career services at institutions are almost exclusively directed at undergraduates. Political science students will need to depend on services offered at a school/college or campus level, assuming that such things exist. Ideally these would include advising, job boards, workshops on non-academic employment, career exploration groups, and access to job fairs targeted at doctoral students. Economies of scale suggest that graduate colleges or other campus-level entities might be best positioned to fill these needs.

Any initiative organized at the trans-departmental level runs the risk of falling into a "one size fits all" trap (especially at a comprehensive university). It also would require additional staffing and cost to be effective. Perhaps equally important, this is an adaptation not in the control of political science departments.

For most graduate faculty members, secure in their own positions and preoccupied with their own lives and careers, it is easy to ignore the shrinking academic market for doctoral students. Nevertheless, political science departments cannot continue with business as usual. The purpose of this essay was not only to raise the issue, but offer some adaptations that are available. Not all might be desirable, but the status quo is not sustainable in either the short or long run.

The views and opinions expressed here are those of the author and do not necessarily reflect the position of APSA.

\section{BOOKS BY OUR MEMBERS}

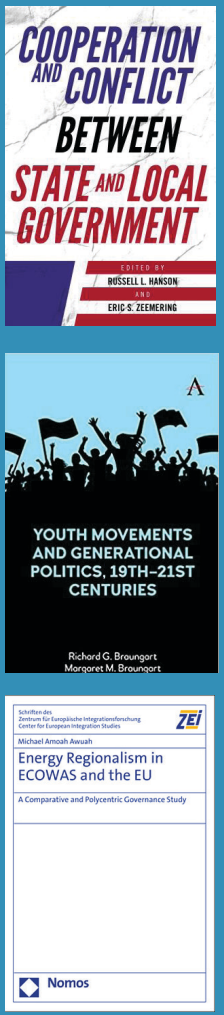

Cooperation and Conflict Between State and Local Government

Edited by Russell L. Hanson and Eric S. Zeemering Rowman \& Littlefield

Youth Movements and Generational Politics, 19th-21 st Centuries

Edited by Richard G. Braungart and Margaret M. Braungart Anthem Press

Energy Regionalism in ECOWAS and the EU Michael Amoah Awuah NOMOS VERLAG

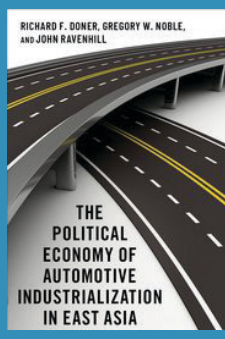

The Political Economy of Automotive Industrialization in East Asia Richard F. Doner, Gregory W. Noble, and John Ravenhill Oxford University Press

On the Fall of the Roman Republic: Lessons for the American People Thomas E. Strunk Anthem Press

Contesting the Global Order

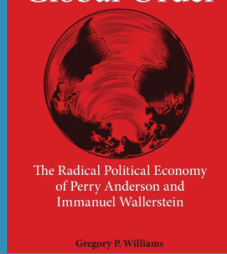

Contesting the Global Order Gregory P. Williams

State University of New York Press 